\title{
Nanoscale Engineering of Hybrid Magnetite-Carbon Nanofibre Materials for Magnetic Resonance Imaging Contrast Agents
}

Olga N. Metelkina, ${ }^{a, b}$ Rhys W. Lodge, ${ }^{c}$ Polina G. Rudakovskaya, ${ }^{a, b}$ Vasiliy M. Gerasimov, ${ }^{a}$ Carlos Herreros Lucas, ${ }^{\mathrm{c}}$ Ivan S. Grebennikov, ${ }^{\mathrm{a}}$ Igor V. Shchetinin, ${ }^{\mathrm{a}}$ Alexander G. Savchenko, ${ }^{\mathrm{a}}$ Galina E. Pavlovskaya, ${ }^{d}$ Graham A. Rance, ${ }^{c}$ Maria del Carmen Gimenez-Lopez, ${ }^{c}$ Andrei N. Khlobystov, ${ }^{\mathrm{a}, \mathrm{c} *}$ Alexander G. Majouga, ${ }^{\mathrm{a}, \mathrm{b}}$

\author{
${ }^{a}$ MISiS, Leninskiy prospekt 2, Moscow 119049, Russia \\ ${ }^{b}$ Chemistry Department, Lomonosov Moscow State University, Moscow 119991, Russia

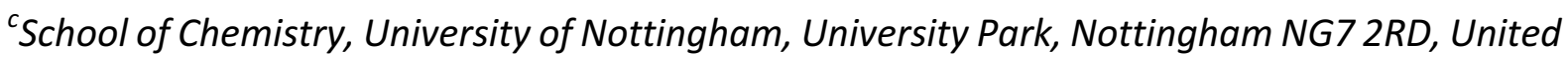 \\ Kingdom
}

${ }^{d}$ Sir Peter Mansfield Imaging Centre, School of Medicine, University of Nottingham, University Park, Nottingham NG7 2RD, United Kingdom

\begin{abstract}
Magnetic nanomaterials show significant promise as contrast agents for magnetic resonance imaging (MRI). We have developed a new highly efficient one-step procedure for the synthesis of magnetically-functionalised hollow carbon nanofibres, where (i) the carbon nanofibres act as both a template and a support for the nucleation and growth of magnetite nanoparticles and (ii) the structural (size, dispersity and morphology) and functional (magnetisation and coercivity) properties of the magnetic nanoparticles formed on nanofibres are strictly controlled by the mass ratio of the magnetite precursor to the nanofibres and the solvent employed during synthesis. We have shown that our magnetitenanofibre materials are effectively solubilised in water resulting in a stable suspension that has been employed as a "negative" MRI contrast agent with an excellent transverse relaxivity $\left(r_{2}\right)$ of $(268 \pm 13) \mathrm{mM} / \mathrm{s}$, surpassing current commercial materials and state-of-the-art magnetic nanoscale platforms in performance for MRI contrast at high magnetic fields. The
\end{abstract}


preparation and evaluation of this unique hybrid nanomaterial represents a critical step towards the realisation of a highly efficient "smart" MRI theranostic agent - a material that allows for the combined diagnosis (with MRI), treatment (with magnetic targeting) and follow-up of a disease (with MRI) - currently in high demand for various clinical applications, including personalised nanomedicine.

Keywords: nanoparticle, nanofibre, carbon nanotube, magnetism, magnetic resonance imaging.

\section{Introduction}

Hollow one-dimensional carbon nanostructures, such as carbon nanotubes (CNTs) and graphitised nanofibres (GNFs), are chemically stable and mechanically robust and have been demonstrated as effective containers for functional molecules and nanoparticles. ${ }^{1-5}$ Whilst much of the current literature has focussed on the applications of narrow CNT as containers, comparatively little attention has been paid to GNFs. These unique hybrid carbon nanostructures comprise an atomically-smooth multi-walled nanotube exterior and a cupstacked interior which gives rise to internal graphitic protrusions, approximately $3.5 \mathrm{~nm}$ in height and spaced at 8-15 nm intervals along the nanofibre growth axis, where localised van der Waals forces are maximised and molecules and nanoparticles become spontaneously immobilised (Figure 1). ${ }^{6-8}$
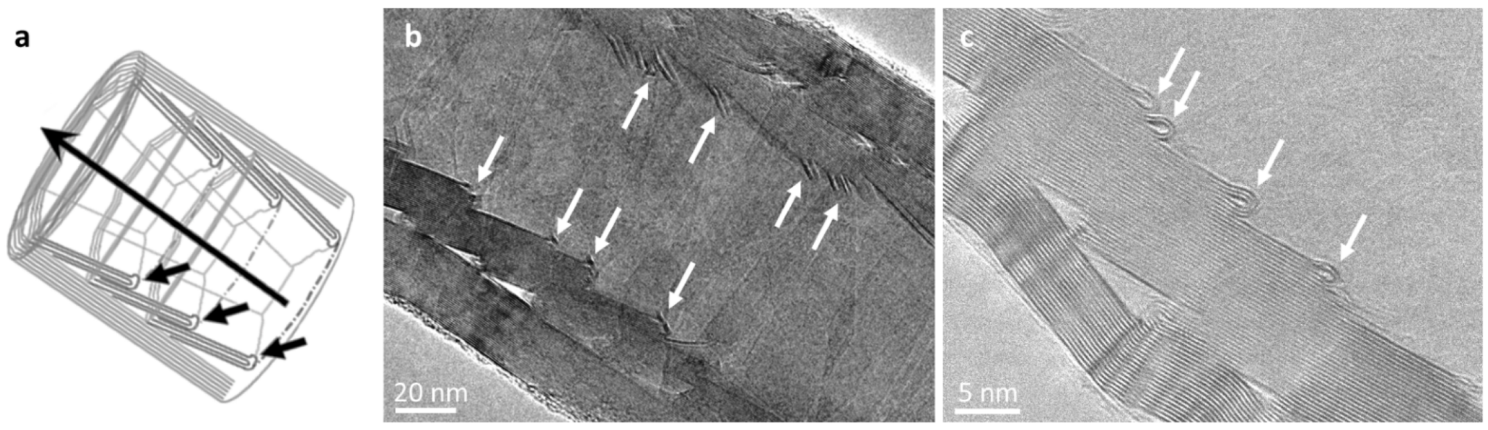

Figure 1. (a) Schematic representation and (b and $\mathbf{c}$ ) transmission electron microscope (TEM) micrographs highlighting the unique structure of graphitised nanofibres. The step-edge arrangement, 
denoted by the small black arrows in (a) and the white arrows in ( $b$ and c), provides an area for both molecules and nanoparticles species to be selectively deposited.

Unlike CNTs, which require opening and have an internal diameter of a few nanometres, graphitised nanofibres are always open and have comparatively large accessible internal volumes, often more than $50 \mathrm{~nm}$ in diameter, allowing for the rapid, uninhibited diffusion of molecules and nanoparticles into the nanofibres. These distinguishing properties of GNFs make them superior to CNT and thus ideal vessels for magnetic resonance imaging (MRI) contrast materials, such as magnetite nanoparticles $\left(\mathrm{Fe}_{3} \mathrm{O}_{4} \mathrm{NP}\right)$. Magnetite composites have shown significant promise for MRI methods due to their excellent magnetic characteristics, such as high magnetic saturation; ${ }^{9-11}$ however, the magnetic properties of $\mathrm{Fe}_{3} \mathrm{O}_{4}$ are highly dependent on the size, shape, crystallinity and purity of magnetite nanoparticles and their distribution on a given substrate. ${ }^{12,13}$ The current challenge for magnetite-based MRI contrast agents is to engineer $\mathrm{Fe}_{3} \mathrm{O}_{4}$ nanostructures to maximise the rate of transverse relaxation $\left(\mathrm{R}_{2}\right)$ whilst maintaining a low concentration of magnetite in the system.

In this comparative study, we appraise the structural and magnetic properties of a series of magnetite nanoparticle/graphitised nanofibre composites ( $\mathrm{Fe}_{3} \mathrm{O}_{4} \mathrm{NP} / \mathrm{GNF}$ ) prepared by simple one-step procedures involving readily accessible reagents. Despite the fact that the formation of $\mathrm{Fe}_{3} \mathrm{O}_{4} \mathrm{NP}$ on CNTs has been extensively studied previously; ${ }^{14-27}$ surprisingly, little investigation has been performed on the formation of magnetite on and in GNFs to date. ${ }^{28-31}$ Herein, we demonstrate that GNFs serve as effective templates for the in-situ formation of $\mathrm{Fe}_{3} \mathrm{O}_{4}$ nanoparticles. We show that reaction conditions, such as the ratio of GNF to iron precursor and the solvent system employed, have a significant effect on the size and morphology of $\mathrm{Fe}_{3} \mathrm{O}_{4}$ in the afforded GNF hybrids. Moreover, we observe that materials with larger, sparsely distributed, magnetite nanoparticles on GNF showed the best magnetic characteristics for MRI and thus the greatest potential for dual functionality theranostics. 


\section{Experimental}

\subsection{General Experimental}

Graphitised nanofibres (PR19 Pyrograf Products, produced by chemical vapour deposition, mean length $\sim 5$ microns, mean inner and outer diameters are $\sim 50$ and $\sim 120 \mathrm{~nm}$ respectively) were purchased from Applied Science, USA. All other reagents and solvents were purchased from Sigma-Aldrich, UK and used without further purification. Water was purified (> 18.0 M $\Omega$ $\mathrm{cm}$ ) using a Barnstead NANOpure II system. High resolution transmission electron microscopy (HRTEM) was performed using a JEOL 2100F transmission electron microscope (field emission electron gun source, information limit $0.19 \mathrm{~nm}$ ). Statistical analysis of nanoparticle diameter $\left(d_{N P}\right)$ was conducted using GatanDigitalMicrograph software $(N>200)$. Energy dispersive $X-$ ray (EDX) analysis was performed using an Oxford Instruments INCA 560 X-ray microanalysis system. TEM/EDX specimens were prepared by casting several drops of methanolic solutions onto copper-grid- or nickel-grid-mounted "holey" carbon films and drying under a stream of nitrogen. Thermogravimetric analysis was determined using a TA Instrument equipped with a SDT Q600 Analyser under flowing air at a rate of $10{ }^{\circ} \mathrm{C} \mathrm{min}^{-1}$ up to $800{ }^{\circ} \mathrm{C}$. Raman spectroscopy was conducted using a Horiba-Jobin-YvonLabRAM HR spectrometer, with a laser wavelength of $532 \mathrm{~nm}$ operating at a power of $c a .4 \mathrm{~mW}$ and a 600 lines $\mathrm{mm}^{-1}$ grating. The detector was a Synapse CCD detector. Spectra were collected by averaging 8 acquisitions of $60 \mathrm{~s}$ duration. The Raman shift was calibrated using the Raleigh peak and the $520.7 \mathrm{~cm}^{-1}$ silicon line from an Si(100) reference sample. Measurement of the magnetic properties was performed using PPMS-9 (Physical Property Measurement System, EverCool II, Quantum Design) in magnetic fields up to 9 T. XRD measurements were carried out using a Rigaku Ultima IV X-ray diffractometer in the Bregg-Brentano recording geometry with $\mathrm{CO}_{\mathrm{K \alpha}}$ radiation with a graphite monochromator on the diffracted beam. A Fisherbrand Accuspin centrifuge was used at $6080 \mathrm{xg}$ during purification of the composite materials.

\subsection{Preparation of $\mathrm{Fe}_{3} \mathrm{O}_{4} \mathrm{NP} / \mathrm{GNF}$}

The preparation of $\mathrm{Fe}_{3} \mathrm{O}_{4} \mathrm{NP} / \mathrm{GNF}$ was achieved through modification of the procedure outlined by Chen et al. ${ }^{32} \mathrm{GNFs}\left(25 \mathrm{mg}\right.$ ) were heated at $400{ }^{\circ} \mathrm{C}$ for $1 \mathrm{~h}$ to remove any residual moisture from the internal channel. To this was added a solution of iron(III) acetylacetonate 
$(25 \mathrm{mg})$ in deionised water $(6 \mathrm{~mL})$ and the suspension sonicated at room temperature for $2 \mathrm{~h}$. The solvent was removed in vacuo and the resulting solid heated from room temperature to $140{ }^{\circ} \mathrm{C}$ at a rate of $2.5^{\circ} \mathrm{C} \mathrm{min}^{-1}$ and then held at $140{ }^{\circ} \mathrm{C}$ for $8 \mathrm{~h}$ in air. The solid was subsequently further heated to $350{ }^{\circ} \mathrm{C}$ at a rate of $2{ }^{\circ} \mathrm{C} \mathrm{min}-1$ under a continuous flow of argon and held at $350{ }^{\circ} \mathrm{C}$ for an additional $3 \mathrm{~h}$. Other materials reported in this work with differing ratios of $\mathrm{Fe}(\mathrm{acac})_{3}$ to GNF and solvent (Table 1 ) were prepared in a similar fashion.

\subsection{Biological applications}

\subsubsection{Dispersion of $\mathrm{Fe}_{3} \mathrm{O}_{4} \mathrm{NP} / \mathrm{GNF}$ for biological applications}

To $\mathrm{Fe}_{3} \mathrm{O}_{4} \mathrm{NP} / \mathrm{GNF}-1: 2 \mathrm{w}(5 \mathrm{mg})$ was added an aqueous solution of Pluronic F-127 (10 mL, $2 \%$ $\mathrm{v} / \mathrm{v}$ ) and the mixture sonicated for $2 \mathrm{~h}$ at room temperature. After sonication, the dispersion was centrifuged $(6,080 \mathrm{xg}, 20 \mathrm{~min})$. Following centrifugation, the supernatant and precipitate were separated by decantation. The supernatant was discarded and the precipitate redispersed in the same volume of deionised water and centrifuged again. This procedure was repeated three times to yield a stable dispersion of $\mathrm{Fe}_{3} \mathrm{O}_{4} / \mathrm{GNF}$ :Pluronic in deionised water. The percentage of Pluronic $\mathrm{F}-127$ in the final $\mathrm{Fe}_{3} \mathrm{O}_{4} / \mathrm{GNF}$ composite was determined by thermogravimetric analysis of the solid prior to the final re-dispersion in water and found to be $3.6 \%$.

Five $10 \mathrm{~mL}$ vials of $\mathrm{Fe}_{3} \mathrm{O}_{4} \mathrm{NP} / \mathrm{GNF}-1: 2 \mathrm{w}$ :Pluronic $\mathrm{F}-127$ were prepared by dilution of the stock solution to five different concentrations for the use in the MRI experiments.

\subsubsection{MRI experiments}

MRI characterisation was performed using a 9.4 T Avance III micro-imaging system (Bruker, Germany). A $30 \mathrm{~mm}$ micro-imaging ${ }^{1} \mathrm{H}$ coil was used in all experiments. Standard MSME (Multi-Slice Multi-Echo) imaging protocol was used for simultaneous spatial mapping of either longitudinal $\left(T_{1}\right)$ or transverse $\left(T_{2}\right)$ time constants of water protons from five different aqueous dispersions of $\mathrm{Fe}_{3} \mathrm{O}_{4} \mathrm{NP} / \mathrm{GNF}-1$ :2w:Pluronic F-127 containing 0.0024561, 0.0064311, $0.0128622,0.0184211$ and $0.0385866 \mathrm{mM}$ of Fe ion. $\mathrm{T}_{1}$ time constants were measured using saturation recovery method with 15 pre-pulses at time to echo (TE) of $9.7 \mathrm{~ms}$. At least five 
recycle delays were used to ensure full characterization of the mono-exponential longitudinal recovery. $T_{2}$ time constants were measured using TEs of 15,50 and $100 \mathrm{~ms}$ and a recycle delay of $3000 \mathrm{~ms}$. A $0.1 \mathrm{~ms}$ bipolar pulse was used for excitation and $1 \mathrm{~ms}$ Gaussian pulse was used for slice selective re-focusing. Data from central $5 \mathrm{~mm}$ axial slices were collected into $128 \times 128$ matrices with isotropic field of view (FOV) of $30 \mathrm{~mm}^{2}$, resulting in raw spatial resolution of $0.234 \mathrm{~mm}^{2}$. Data were zero filled to $256 \times 256$ before image reconstruction. Images were reconstructed using Prospa 3.1 (Magritek, New Zealand). $T_{1}$ and $T_{2}$ data analysis was performed using IgorPro 6.1 (Wavemetrics, USA). $T_{1}$ and $T_{2}$ time constants were determined in each phantom using pixel by pixel linear fitting after transforming the data into semilogarithmic scale as mono-exponential proton relaxation behaviour was assumed. Subsequent determination of the averaged $T_{1}$ and $T_{2}$ values and their variances was performed using Gaussian multi-peak build-in subroutine.

\section{Results and discussion}

The thermal decomposition of iron(III) acetylacetonate $\left(\mathrm{Fe}(\mathrm{acac})_{3}\right)$ was chosen as the ideal method for the preparation of $\mathrm{Fe}_{3} \mathrm{O}_{4}$ nanoparticles owing to its synthetic ease and use of cheap, widely accessible reagents. As Fe(acac $)_{3}$ had to be both deposited on and encapsulated in GNFs to provide the precursor for the nanoparticles, it was, therefore, essential to control the physical properties of the solvent to ensure optimum deposition. We, thus, explored the use of both water and a mixture of water and ethanol for the effective solvation of Fe(acac $)_{3}$. In a typical experiment, the metal complex was dissolved in water or a mixture of water/ethanol $(3 / 1 \mathrm{v} / \mathrm{v})$, GNFs were then immersed in the precursor solutions and mixed under ultrasonic agitation to ensure efficient mixing, followed by evaporation of the solvent to enhance the extent of adsorption of the precursor on the surfaces of GNFs. The GNFs and metal complex were then heated in air and finally in an inert atmosphere to promote the efficient decomposition of $\mathrm{Fe}(\mathrm{acac})_{3}$ to $\mathrm{Fe}_{3} \mathrm{O}_{4}$.

Confirmation of the chemical composition and structure of the resultant nanoparticles in the hybrid structures was afforded by energy dispersive X-ray (EDX) analysis (Figure 2a), X-ray diffraction (XRD) (Figure 2b), Raman spectroscopy (Figure 2c) and high resolution transmission electron microscopy (HRTEM) (Figure 2d). 

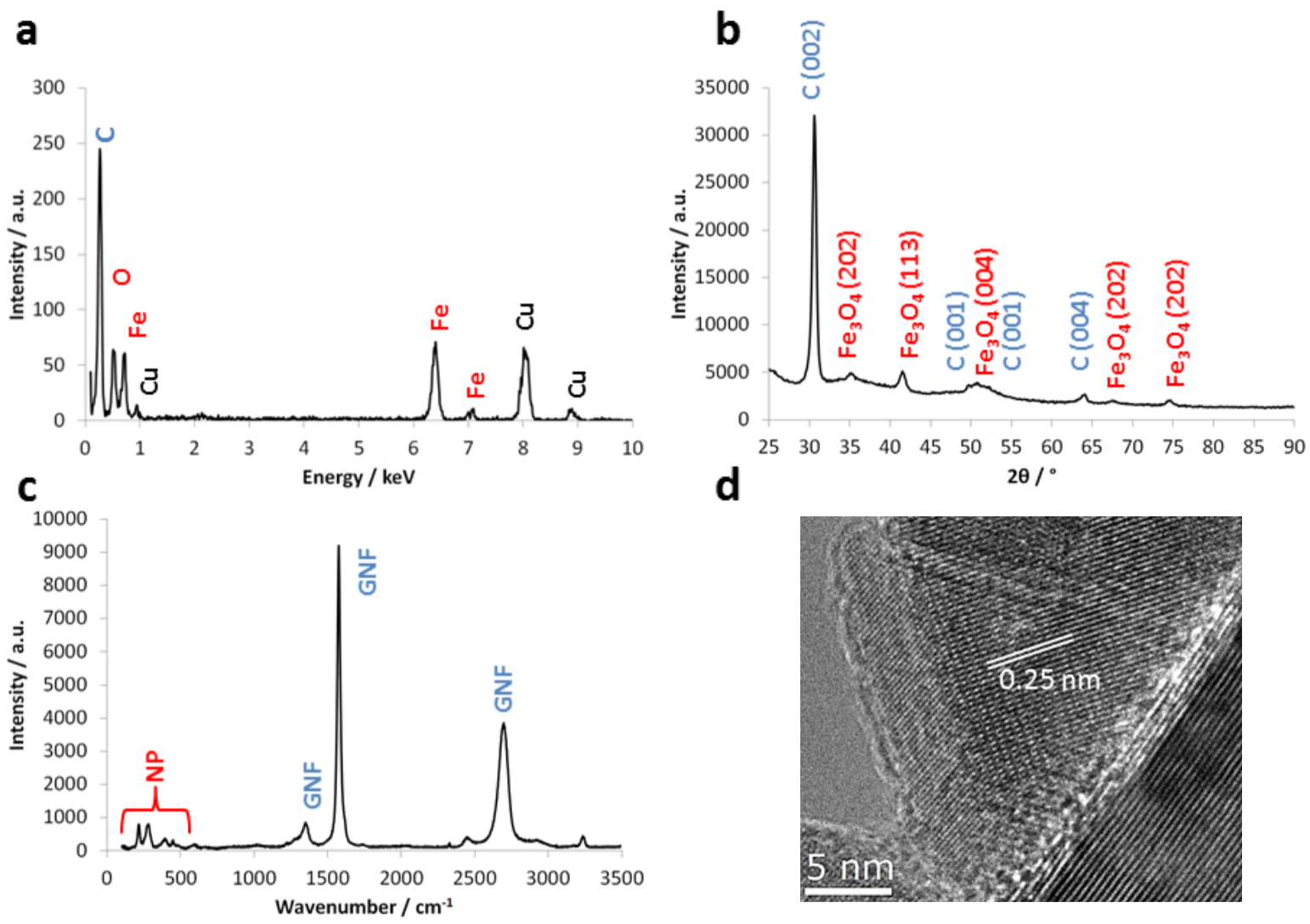

Figure 2. (a) A representative EDX spectrum of the $\mathrm{Fe}_{3} \mathrm{O}_{4} \mathrm{NP} / \mathrm{GNF}$ hybrids. The peaks at $0.71,6.40$ and $7.06 \mathrm{keV}$ correspond to $L \alpha, K \alpha$ and $K \beta$ fluorescence peaks of Fe respectively. The $K \alpha X$-rays of $O$ are observed at $0.53 \mathrm{keV}$. The atomic ratio of $\mathrm{Fe}: \mathrm{O}$ of 3.0:4.2 matches well with that expected for $\mathrm{Fe}_{3} \mathrm{O}_{4}$, with the slight excess of oxygen attributed to a small degree of surface functionality of the GNF. The large peak at $0.28 \mathrm{keV}$ is due to the Ka X-rays of $\mathrm{C}$ in GNF. The large fluorescence peaks near 8.00 and $8.84 \mathrm{keV}$ are the $\mathrm{K} \alpha$ and $\mathrm{K} \beta \mathrm{X}$-ray fluorescence signatures of $\mathrm{Cu}$ respectively (an artefact induced from either the TEM grid mesh or the instrument column assembly). (b) A representative XRD pattern for $\mathrm{Fe}_{3} \mathrm{O}_{4} \mathrm{NP} / \mathrm{GNF}$ hybrids showing the indexed crystal planes of both $\mathrm{Fe}_{3} \mathrm{O}_{4}$ and GNF. (c) A representative Raman spectrum of the $\mathrm{Fe}_{3} \mathrm{O}_{4}-\mathrm{GNF}$ composite showing bands associated with iron oxide (the peaks at 209, 273, 386 and $577 \mathrm{~cm}^{-1}$ corresponding to one $A_{1 g}$ and three $E_{g}$ modes in haematite, $\alpha-\mathrm{Fe}_{2} \mathrm{O}_{3}$, a known by-product of the heated-induced transformation of $\mathrm{Fe}_{3} \mathrm{O}_{4}$ under the laser irradiation required for Raman spectroscopy analysis) ${ }^{33}$ and GNF (1341, 1562 and $2684 \mathrm{~cm}^{-1}$ corresponding to $D, G$ and 2D modes in graphitic carbon structures respectively). ${ }^{34}$ (d) A representative TEM micrograph of magnetite nanoparticles on the external GNF surface. An interplanar spacing of $0.25 \mathrm{~nm}$ can be observed that is consistent with the (311) $\mathrm{Fe}_{3} \mathrm{O}_{4}$ crystal plane. 
Comparative TEM analysis revealed magnetite nanoparticles on GNF with average sizes of 11 \pm 4 and $14 \pm 3 \mathrm{~nm}$ for the materials prepared with the same mass ratio of $\mathrm{Fe}(\mathrm{acac})_{3}: \mathrm{GNF}$ in water and water/ethanol respectively (Figure 3).
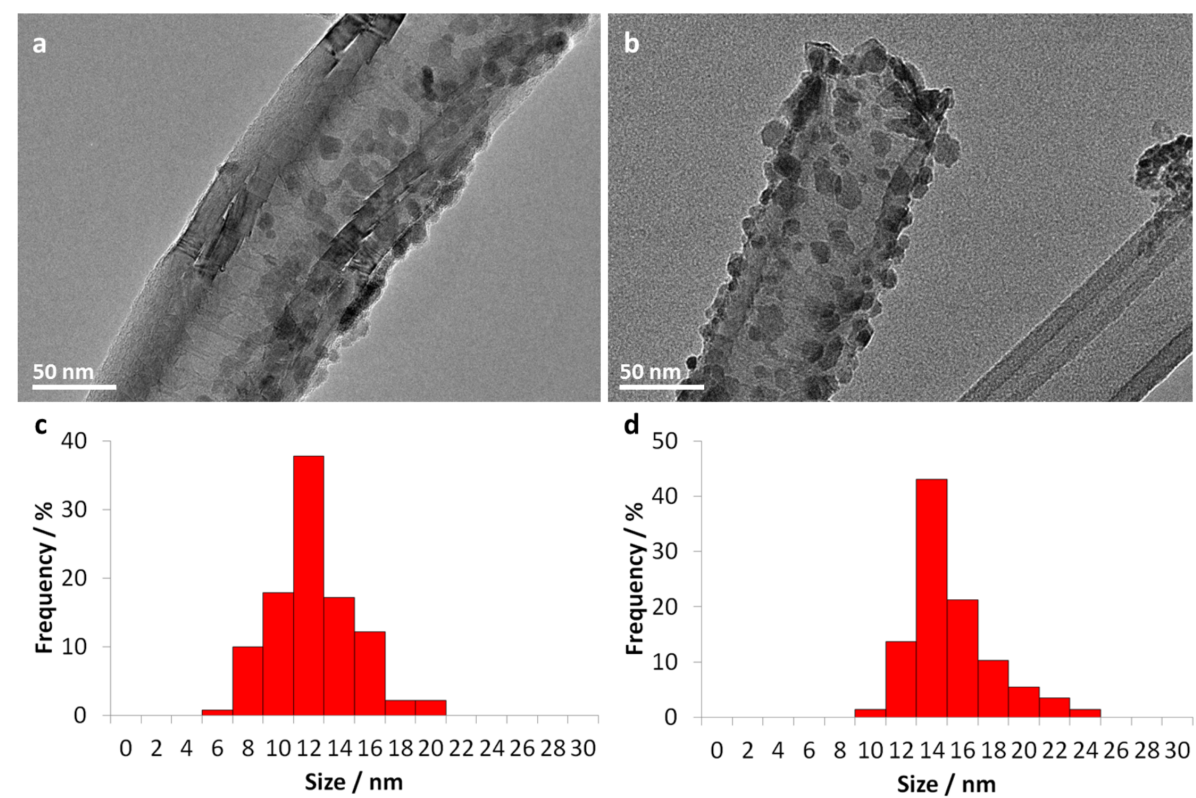

Figure 3. HR-TEM micrographs of $\mathrm{Fe}_{3} \mathrm{O}_{4} \mathrm{NP} / \mathrm{GNF}$ prepared using the same ratio of iron precursor to GNF (Fe(acac) $3: G N F, 1: 1$ ) but using different solvent systems: (a) sample $\mathrm{Fe}_{3} \mathrm{O}_{4} N P / G N F-1: 1 \mathrm{w}$, where $d_{N P}=11 \pm 4 \mathrm{~nm}$; (b) sample $\mathrm{Fe}_{3} \mathrm{O}_{4} \mathrm{NP} / \mathrm{GNF}-1: 1$ ew where $d_{N P}=14 \pm 3 \mathrm{~nm}$. The corresponding particle size distributions are displayed in (c) and (d) respectively.

Analysis of multiple micrographs revealed that a greater proportion of the $\mathrm{Fe}_{3} \mathrm{O}_{4}$ nanoparticles formed by the water/ethanol method appeared to reside on the external surface of the GNFs in comparison to the water method, where the number of nanoparticles confined within the inner channel was higher. Since the surfaces of GNFs are hydrophobic, water/ethanol wets the GNFs more effectively than pure water, allowing for a more even distribution of magnetite. The poor solubility of $\mathrm{Fe}(\mathrm{acac})_{3}$ in water, in conjunction with the hydrophobic properties of the GNFs, permitted a more efficient insertion and deposition of the precursor molecules into the internal channel of the GNFs.

More importantly, magnetic measurements in a $3 \mathrm{~T}$ field (Figure 5) demonstrated that the $\mathrm{Fe}_{3} \mathrm{O}_{4} \mathrm{NP} / \mathrm{GNF}$ hybrid material prepared using the same mass ratio of iron precursor to GNF 
$\left(\mathrm{Fe}(\mathrm{acac})_{3}: \mathrm{GNF}, 1: 1\right)$ if made in water possesses a significantly lower magnetisation $\left(\mathrm{M}_{\mathrm{s}}=51\right.$ and 94 emu/g respectively) and a comparable coercivity $\left(H_{c}=64\right.$ and 31 Oe respectively) relative to $\mathrm{Fe}_{3} \mathrm{O}_{4} \mathrm{NP} / \mathrm{GNF}$ prepared using water/ethanol (Table 1). The observed differences in magnetic behaviour can be readily explained by the distinct structural properties of the hybrid materials. In $\mathrm{Fe}_{3} \mathrm{O}_{4} \mathrm{NP} / \mathrm{GNF}-1: 1 \mathrm{w}$, the mean diameter of nanoparticles is $11 \pm 4 \mathrm{~nm}$ (above the critical diameter for magnetite to exist in a superparamagnetic state of $d_{\mathrm{sp}} \lesssim 9$ $\mathrm{nm})^{35}$ and the density of the nanoparticles on GNF is low (only 140 per $1 \mu \mathrm{m}$ of GNF length). Consequently, there are only weak magnetostatic interactions between neighbouring nanoparticles, with approximately $50 \%$ of the nanoparticles existing in a superparamagnetic state even in the $3 \mathrm{~T}$ field as evident from the measured magnetisation which, therefore, do not contribute to the total magnetisation of the hybrid material.

As a consequence, water was used to prepare a series of samples to explore the effects of the ratio of the magnetite precursor to GNFs. Using different starting ratios of $\mathrm{Fe}(\mathrm{acac})_{3}$ to GNFs allows for the control of not only the size and shape of $\mathrm{Fe}_{3} \mathrm{O}_{4}$ nanoparticle, but also potentially their distribution along the GNF and relative positions with respect to each other. More widely distributed and slightly larger nanoparticles are expected to have a larger surface of interaction with surrounding water molecules in MRI experiments, which should yield better contrast. We investigated three different mass ratios of $\mathrm{Fe}(\mathrm{acac})_{3}: \mathrm{GNF}, 1: 2,1: 1$ and 2:1, showing that the average nanoparticle size varies from 8 to $14 \mathrm{~nm}$ across the series (Figure 4).
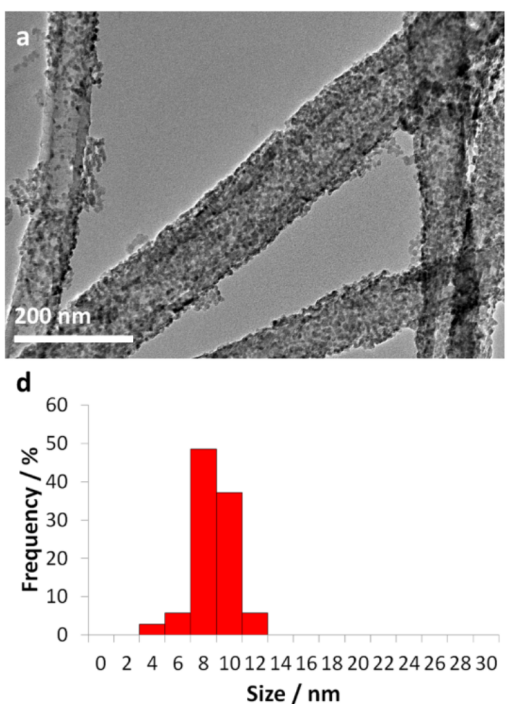
Size / $\mathrm{nm}$
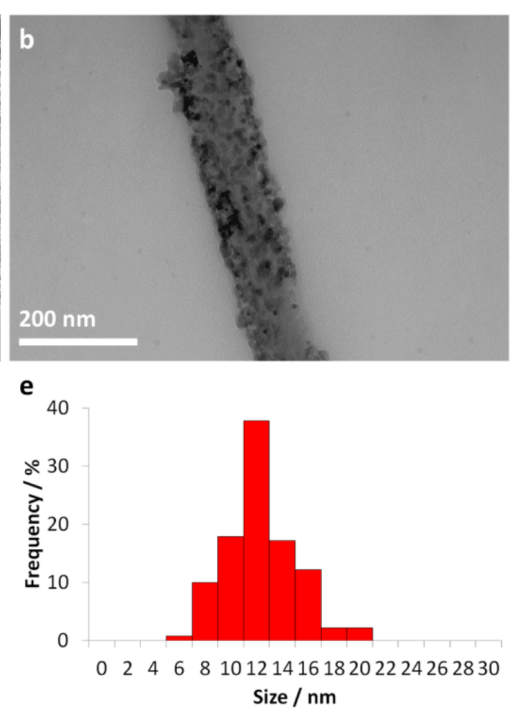
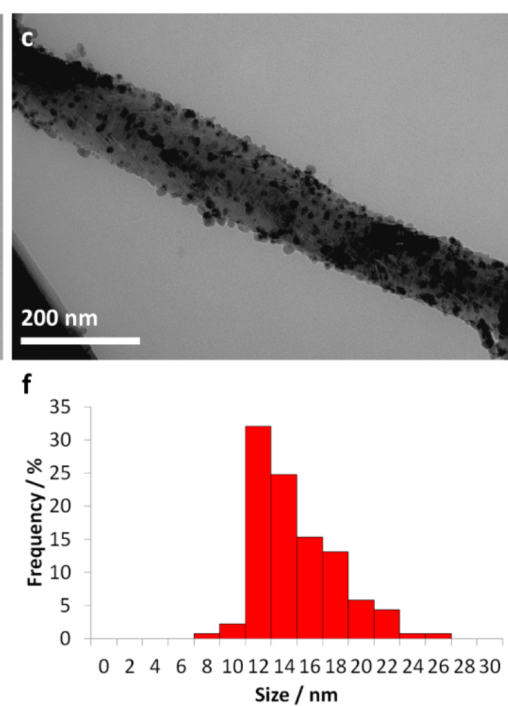
Figure 4. HR-TEM micrographs of $\mathrm{Fe}_{3} \mathrm{O}_{4} \mathrm{NP} / \mathrm{GNF}$ prepared using three different mass ratios of $\mathrm{Fe}(\text { acac) })_{3}: G N F$ : (a) $\mathrm{Fe}_{3} \mathrm{O}_{4} N P / G N F-2: 1 \mathrm{w}$, where $\mathrm{d}_{\mathrm{NP}}=8 \pm 1 \mathrm{~nm}$; (b) $\mathrm{Fe}_{3} \mathrm{O}_{4} N P / G N F-1: 1 \mathrm{w}$, where $\mathrm{d}_{\mathrm{NP}}=11$ $\pm 4 \mathrm{~nm}$ and (c) $\mathrm{Fe}_{3} \mathrm{O}_{4} \mathrm{NP} / \mathrm{GNF}-1: 2 \mathrm{w}$, where $\mathrm{d}_{\mathrm{NP}}=14 \pm 3 \mathrm{~nm}$, using water as the solvent. The corresponding particle size distributions are displayed in (d), (e) and (f) respectively.

There is a clear relationship between the average nanoparticle size and the ratio of $\mathrm{Fe}(\mathrm{acac})_{3}: \mathrm{GNF}$. We observe that the higher the ratio of the precursor, i.e. a greater number of nucleation centres on GNFs, leads to a larger number of particles with a smaller average size and, therefore, a narrower particle size distribution (Table 1).

Table 1. Conditions used for the synthesis and the resultant properties of the $\mathrm{Fe}_{3} \mathrm{O}_{4} \mathrm{NP} / \mathrm{GNF}$ hybrid materials.

\begin{tabular}{|c|c|c|c|c|c|c|}
\hline Material & $\begin{array}{l}\mathrm{Fe}(\mathrm{acac})_{3}: \\
\text { GNF (w:w) }\end{array}$ & Solvent & $\begin{array}{c}\mathrm{d}_{\mathrm{NP}} / \\
\mathrm{nm}\end{array}$ & $\begin{array}{l}\text { Density / } \\
\text { NP } \mu^{-1}\end{array}$ & $\begin{array}{c}\text { Magnetic } \\
\text { moment / emu } \\
\mathbf{g}^{-1}\end{array}$ & $\begin{array}{c}\text { Coercivity, } \\
\text { Oe }\end{array}$ \\
\hline $\mathrm{Fe}_{3} \mathrm{O}_{4} \mathrm{NP} / \mathrm{GNF}-1: 2 \mathrm{w}$ & $1: 2$ & water & $14 \pm 3$ & 310 & 99 & 173 \\
\hline $\mathrm{Fe}_{3} \mathrm{O}_{4} \mathrm{NP} / \mathrm{GNF}-1: 1 \mathrm{w}$ & 1:1 & water & $11 \pm 4$ & 140 & 51 & 64 \\
\hline $\mathrm{Fe}_{3} \mathrm{O}_{4} \mathrm{NP} / \mathrm{GNF}-2: 1 \mathrm{w}$ & $2: 1$ & water & $8 \pm 1$ & $>1000$ & 83 & 82 \\
\hline $\mathrm{Fe}_{3} \mathrm{O}_{4} \mathrm{NP} / \mathrm{GNF}-1: 1 \mathrm{ew}$ & $1: 1$ & $\begin{array}{c}\text { ethanol / } \\
\text { water }\end{array}$ & $14 \pm 3$ & 370 & 94 & 51 \\
\hline
\end{tabular}

Most significantly, $\mathrm{Fe}_{3} \mathrm{O}_{4} \mathrm{NP} / \mathrm{GNF}$ prepared in a 1:2 mass ratio has nanoparticles that are well dispersed (Figure 4c) due to the large surface of the GNF. Furthermore, evaluation of the magnetic properties of these materials yielded key insight into the structure-property relationships of nanoscale magnetic materials. For example, $\mathrm{Fe}_{3} \mathrm{O}_{4} \mathrm{NP} / \mathrm{GNF}-2: 1 \mathrm{w}$ possesses nanoparticles of a mean diameter which is comparable or below the critical diameter $d_{s p}$ required for the transition of magnetite to the superparamagnetic state and can thus explain the high magnetisation of this material. Furthermore, a high density of nanoparticles on the surface of GNF in this material (>1000 per $1 \mu \mathrm{m}$ of GNF length) provides strong magnetostatic interactions between them, which can be further enhanced by very effective dispersion 
interactions between $\mathrm{Fe}_{3} \mathrm{O}_{4} \mathrm{NP}$ and GNF leading to an increase of the surface magnetic anisotropy parameter. All these phenomena can lead to an increase of the magnetic anisotropy constant and 'freezing' of the magnetic moments of many nanoparticles in this material (the estimated volume fraction of nanoparticles existing in the superparamagnetic state is below $10 \%$ ). Overall, both the magnetization and the coercive force of $\mathrm{Fe}_{3} \mathrm{O}_{4} \mathrm{NP} / \mathrm{GNF}-$ 2:1w are enhanced as a result. Conversely, $\mathrm{Fe}_{3} \mathrm{O}_{4} \mathrm{NP} / \mathrm{GNF}-1: 2 \mathrm{w}$ possess relatively large nanoparticles, with a comparatively lower density of nanoparticles on the surface of GNF, leading to weaker magnetostatic interactions and thus more attractive magnetic properties (Figure 5).

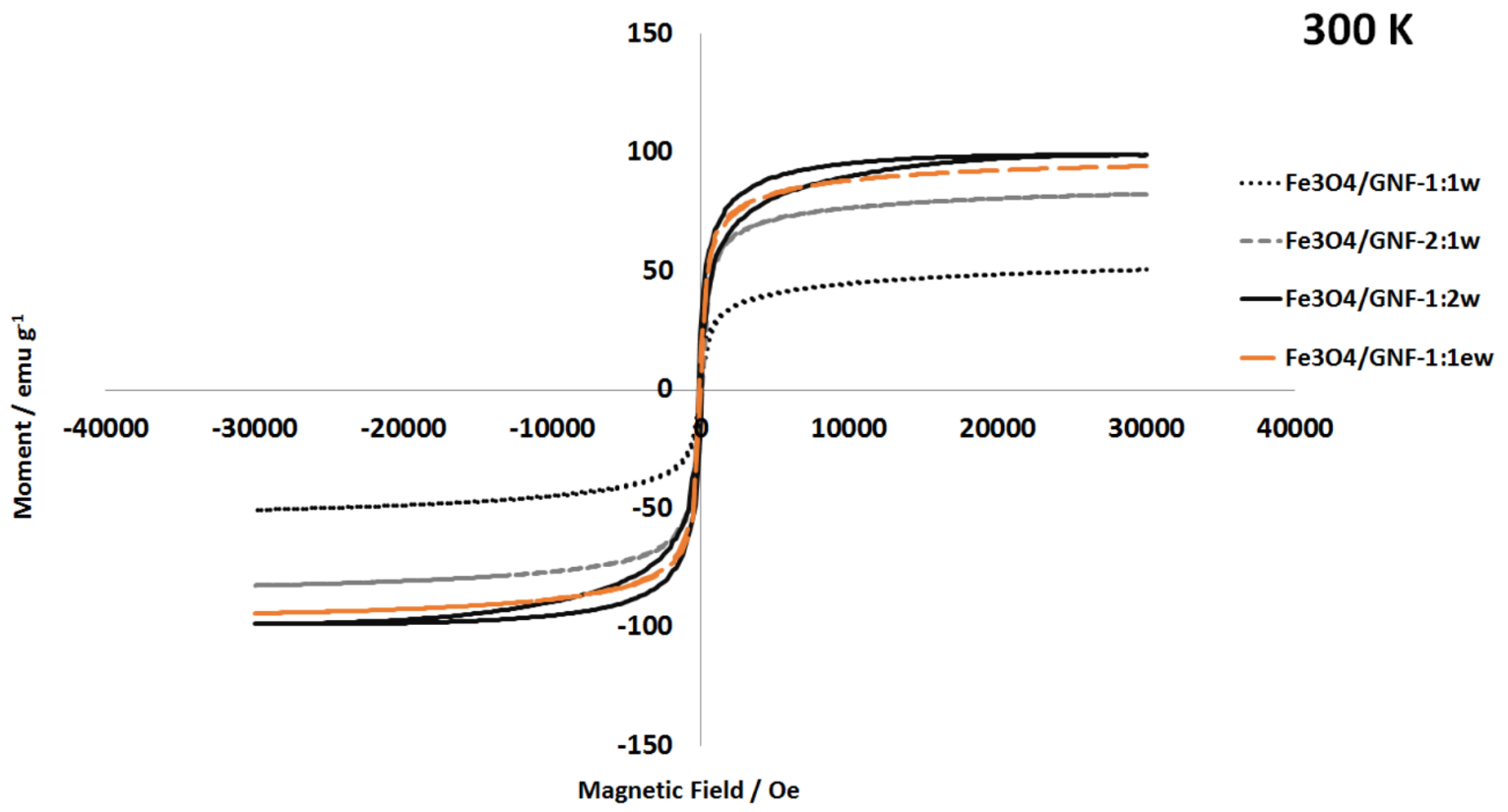

Figure 5. Magnetic properties of $\mathrm{Fe}_{3} \mathrm{O}_{4} \mathrm{NP} / \mathrm{GNF}$ hybrids with varying ratios of $\mathrm{Fe}(\mathrm{acac})_{3}: \mathrm{GNF}$ and solvent systems ( $w$ - water, ew - ethanol/water).

Since the hybrid $\mathrm{Fe}_{3} \mathrm{O}_{4} \mathrm{NP} / \mathrm{GNF}$ material, prepared in water using a 1:2 ratio of $\mathrm{Fe}(\mathrm{acac})_{3}: \mathrm{GNF}$, possesses the most optimum structure and magnetic properties, it was tested as a contrast agent for MRI. However, in order to stabilise $\mathrm{Fe}_{3} \mathrm{O}_{4} \mathrm{NP} / \mathrm{GNF}$ in water, a fundamental requirement for biological applications, Pluronic F-127 was added to the composite material, with the extent of coating confirmed with thermogravimetric analysis to be $11 \%$ by mass. 
The efficiency of MRI contrast agents depends on their longitudinal ( $r 1)$ and transverse $(r 2)$ relaxivities, as well as on their ratio. The efficiency of a $T_{2}$ contrast agent is optimal when $r 2 / r 1$ ratio is the highest. To determine the $\mathrm{r} 2 / \mathrm{r} 1$ ratio in the presence of $\mathrm{Fe}_{3} \mathrm{O}_{4} N P / G N F$, the transverse relaxation $\left(T_{2}\right)$ and longitudinal relaxation $\left(T_{1}\right)$ of water protons in aqueous solutions of solubilised $\mathrm{Fe}_{3} \mathrm{O}_{4} \mathrm{NP} / \mathrm{GNF}$ were studied for a range of concentrations of the added contrast agent. $T_{1}$ and $T_{2}$ weighted images were obtained as described in the Experimental section and $T_{2}$ and $T_{1}$ relaxation maps derived from the resulting images (Figure 6a and c). The inset in Figure 6 lists the Fe cation concentrations in five aqueous samples of $\mathrm{Fe}_{3} \mathrm{O}_{4} \mathrm{NP} / \mathrm{GNF}$ that were used as an imaging phantom. 

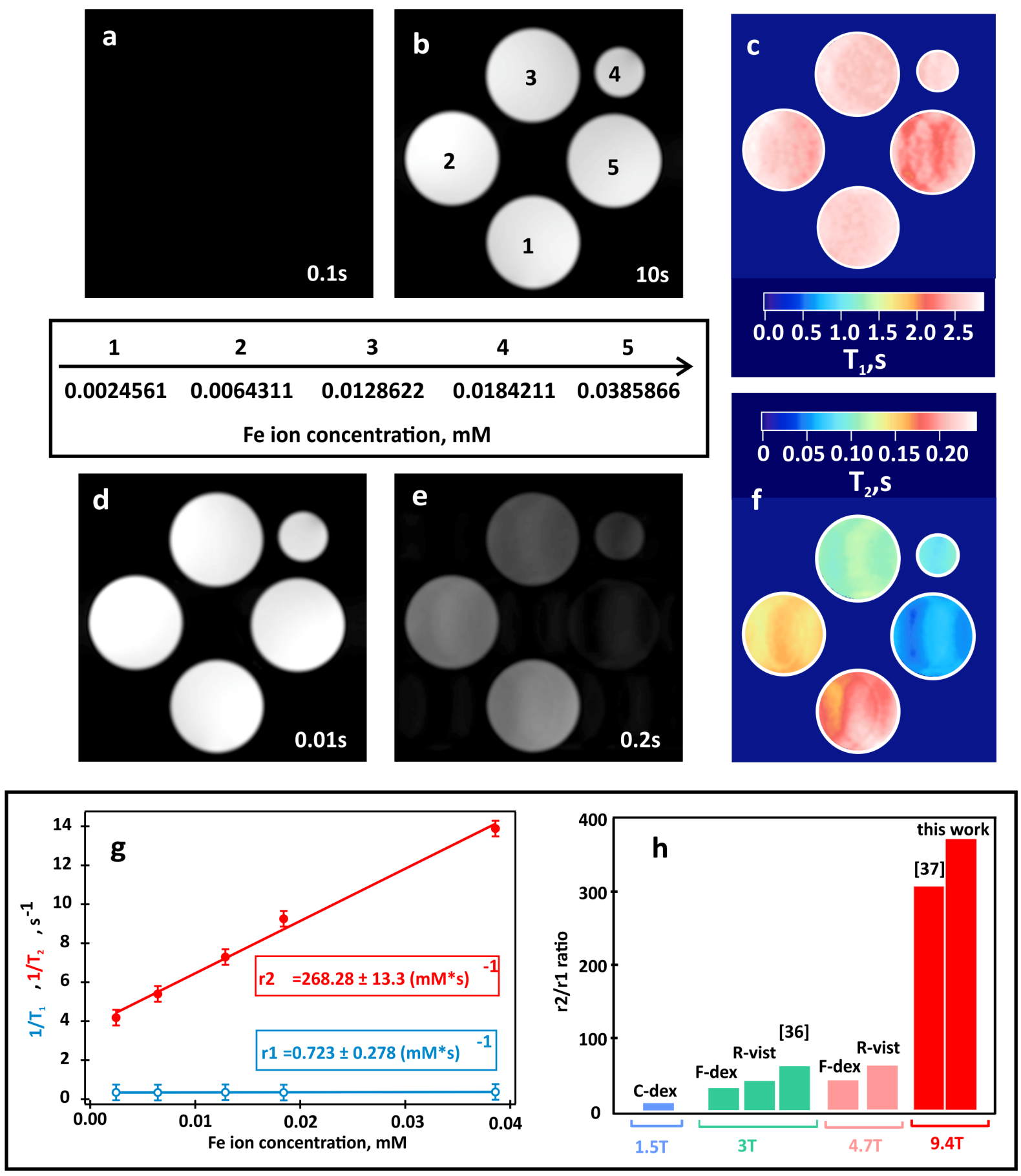

Figure 6. Longitudinal ( $r 1$ ) and transverse ( $r 2$ relaxivity of water in the presence of $\mathrm{Fe}_{3} \mathrm{O}_{4} \mathrm{NP} / \mathrm{GNF}$ 1:2w:Pluronic F-127 at 9.4T: (a) - (b) saturation recovery images of water phantoms containing five different concentrations of $\mathrm{Fe}_{3} \mathrm{O}_{4} \mathrm{NP} / \mathrm{GNF}-1: 2 \mathrm{w}$ :Pluronic F-127 at two recovery delay times. Please note that the recovery at 10 s is independent of the Fe ion content in each tube. The Fe ion content in each tube is shown in the inset; (c) $T_{1}$ relaxation map demonstrating the limited dependence of the longitudinal relaxation on the $\mathrm{Fe}$ ion content in phantoms; (d) - (e) spin echo images of water phantoms with the same Fe ion content as in (a) - (c); (f) corresponding $T_{2}$ map obtained using $T_{2}$ data analysis in each sample tube as described in the Experimental section. The following transverse 
relaxation time constants are obtained after: $(1)$ red $-(0.239 \pm 0.17) \mathrm{s}$; (2) yellow $-(0.185 \pm 0.010) \mathrm{s}$; (3) light green - $(0.137 \pm 0.010) \mathrm{s}$; (4) light blue - $(0.108 \pm 0.090) \mathrm{s}$; (5) dark blue - $(0.072 \pm 0.010) \mathrm{s}$; (g) transverse (red) and longitudinal (blue) relaxation rates as a function of iron content in the added contrast agent. Relaxivity is the slope extracted from linear fitting of the data; (h) comparison of $\mathrm{r} 2 / \mathrm{r} 1$ ratio for commercial Combidex (C-dex), Feridex (F-dex), Resovist (R-vist) ${ }^{36}$ and novel NP based contrast $\mathrm{MRI}$ agents ${ }^{37}$ relative to this work at different magnetic field strengths.

The influence of the added contrast agent on the transverse proton relaxation is highlighted in Figure 6a. It is apparent that $T_{2}$ decreases with a corresponding increase of the iron concentration in the added contrast agent. On the contrary, the $T_{1}$ map displayed in Figure $6 \mathrm{c}$ shows mediocre dependence of the longitudinal relaxation on the iron content for the same range of concentration of the added contrast agent. To determine $r 1$ and $r 2$ relaxivities we analysed the dependence of the relaxation rates $r_{1}\left(=1 / T_{1}\right)$ and $r_{2}\left(=1 / T_{2}\right)$ on the iron ion concentration in the added contrast agent (Figure $6 \mathrm{~g}$ ). The relaxivities $r 1$ and $r 2$ were determined by linear fitting the data displayed in Figure $6 \mathrm{~g}$ and resulted in $r 1=(0.7 \pm 0.3)$ $\mathrm{mM} / \mathrm{s}$ and $\mathrm{r} 2=(268 \pm 13) \mathrm{mM} / \mathrm{s}$. The determined $\mathrm{r} 2 / \mathrm{r} 1$ ratio is $380 \pm 26$ demonstrates that aqueous $\mathrm{Fe}_{3} \mathrm{O}_{4} \mathrm{NP} / \mathrm{GNF}-1: 2 \mathrm{w}$ :Pluronic $\mathrm{F}-127$ surpasses the best commercially available agent (Resovist) by at least a factor of 6 . This ratio is also higher (380 vs 306) than that reported for state-of-the-art magnetic nanoscale platforms ${ }^{37}$ specifically designed for optimal performance at ultra-high (9.4T) magnetic field. This value highlights the great potential of $\mathrm{Fe}_{3} \mathrm{O}_{4} \mathrm{NP} / \mathrm{GNF}$ as "smart" contrast agents in in vivo research at ultra-high magnetic fields (7T and higher) as the majority of pre-clinical scanners operate at these field strengths. ${ }^{38}$ With the further development of "smart" theranostic agents, like the one proposed here, the potential mechanism for personalised nanomedicine could be more efficiently explored in

the pre-clinical setting. ${ }^{40,41}$ If successful, this could accelerate the pathway for bringing abdominal theranostics to the patient, of significant benefit due to the ongoing, worldwide rise of ultra-high field (7T) clinical MRI. ${ }^{42,43}$

\section{Conclusions}

In conclusion, we have developed a simple one-step procedure to assemble $\mathrm{Fe}_{3} \mathrm{O}_{4} \mathrm{NP} / \mathrm{GNF}$ hybrid structures from widely available precursors. The influence of solvent, and the ratio of 
starting complex to GNF, has also been studied. An optimised method using a 1:2 mass ratio of Fe(III) acetylacetonate to GNF, prepared using water as the solvent, showed excellent properties as an MRI contrast agent, outperforming commercially available materials and literature analogues. Whilst the issue of biocompatibility of carbon nanotubes and their composites with magnetite nanoparticles still needs further assessment, ${ }^{44-48}$ current literature studies suggest that analogous materials have limited toxicity to healthy and malignant cells and can be injected at a concentration of $2.5 \mathrm{mg}$ of iron per $\mathrm{kg}$ of body weight without any apparent harm to health. ${ }^{49,50}$ Furthermore, the recent application of magnetic materials in CNTs for cell shepherding and magnetic fluid hyperthermia treatment ${ }^{51}$ represents a significant breakthrough for the safe use of these materials. Thus, when combined with the open internal channel of GNFs, accessible for therapeutic pharmaceutical agent loading alongside the $\mathrm{Fe}_{3} \mathrm{O}_{4}$ nanoparticles, such hybrid nanostructures can offer a novel mechanism for magnetically-induced drug release, in addition to the functional MRI contrast properties, consequently resulting in a potentially indispensable contribution to the emerging area of theranostics.

\section{Acknowledgements}

The authors are grateful to the Nanoscale \& Microscale Research Centre (NMRC) for access to TEM and Raman facilities. This work supported by grant of Russian Federation Ministry of Science and Education Grant № K3-2015-030 (MISiS) and the University of Nottingham Advanced Molecular Materials for Healthcare Research Priority Area.

\section{References}

1. A. N. Khlobystov, D. A. Britz and G. A. D. Briggs, Acc. Chem. Res., 2005, 38, 901-909.

2. D. A. Britz and A. N. Khlobystov, Chem. Soc. Rev., 2006, 35, 637-659.

3. P. Serp and E. Castillejos, ChemCatChem, 2010, 2, 41-27.

4. X. L. Pan and X. H. Bao, Acc. Chem. Res., 2011, 44, 553-562.

5. S. A. Miners, G. A. Rance and A. N. Khlobystov, Chem. Soc. Rev., 2016, 45, 4727-4746. 
6. A. La Torre, M. W. Fay, G. A. Rance, M. D. C. Gimenez-Lopez, W. A. Solomonsz, P. D. Brown and A. N. Khlobystov, Small, 2012, 8, 1222-1228.

7. A. La Torre, M. D. C. Gimenez-Lopez, M. W. Fay, G. A. Rance, W. A. Solomonsz, T. W. Chamberlain, P. D. Brown and A. N. Khlobystov, ACS Nano, 2012, 6, 2000-2007.

8. M. A. Lebedeva, T. W. Chamberlain, A. Thomas, B. E. Thomas, C. T. Stoppiello, E. Volkova, M. Suyetin and A. N. Khlobystov, Nanoscale, 2016, 8, 11727-11737.

9. Z. R. Stephen, F. M. Kievit and M. Zhang, Mater. Today, 14, 330-338.

10. M. A. Abakumov, N. V. Nukolova, M. Sokolsky-Papkov, S. A. Shein, T. O. Sandalova, H. M. Vishwasrao, N. F. Grinenko, I. L. Gubsky, A. M. Abakumov, A. V. Kabanov and V. P. Chekhonin, Nanomed., 2015, 11, 825-833.

11. C. Felton, A. Karmakar, Y. Gartia, P. Ramidi, A. S. Biris and A. Ghosh, Drug Metab. Rev., 2014, 46, $142-154$

12. P. Guardia, A. Labarta and X. Batlle, J. Phys. Chem. C, 2011, 115, 390-396.

13. A. Demortière, P. Panissod, B. P. Pichon, G. Pourroy, D. Guillon, B. Donnio and S. Bégin-Colina, Nanoscale, 2011, 3, 225-232.

14. L. Jiang and I. Gao, Chem. Mater., 2003, 15, 2848-2853.

15. J. Wan, W. Cai, J. Feng, X. Meng and E. Liu, J. Mater. Chem., 2007, 17, 1188-1192.

16. H. Zhang, N. Du, P. Wu, B. Chen and D. Yang, Nanotechnol., 2008, 19, 315604.

17. D. Yang, F. Yang, J. Hu, J. Long, C. Wang, D. Fu and Q. Ni, Chem. Commun., 2009, 4447-4449.

18. A. Masotti and A. Caporali, Int. J. Mol. Sci., 2013, 14, 24619-24642.

19. Q. Zhang, M. Zhu, Q. Zhang, Y. Li and H. Wang, Compos. Sci. Technol., 2009, 69, 633-638.

20. D. Shi, J. P. Cheng, F. Liu and X. B. Zhang, J. Alloys Compd., 2010, 502, 365-370.

21. O. Vittorio, S. L. Duce, A. Pietrabissa and A. Cuschieri, Nanotechnol., 2011, 22, 095706.

22. G. Lamanna, A. Garofalo, G. Popa, G. Wilhelm, S. Beqin-Colin, D. Felder-Flesch, D. Bianco, F. Gazeau and C. Menard-Moyon, Nanoscale, 2013, 5, 4412-4421.

23. S. Shen, J. Ren, X. Zhu, Z. Pang, X. Lu, C. Deng, R. Zhang and X. Jiang, J. Mater. Chem. B, 2013, 1, 1939-1946.

24. A. Masotti and A. Caporali, Int. J. Mol. Sci., 2013, 14, 24619-24642.

25. J. T.-W. Wang, L. Cabane, M. Bourgognon, H. Kafa, A. Protti, K. Venner, A. M. Shah, J. K. Sosabowski, S. J. Mather, A. Roig, X. Ke, G. van Tendeloo, R. T. M. de Rosales, G. Tobias and K. T. Al-Jamal, Adv. Funct. Mater., 2014, 24, 1880-1894.

26. Y. Liu, B. W. Muir, L. J. Waddington, T. M. Hinton, B. A. Moffat, X. Hao, J. Qiu and T. C. Hughes, Biomacromolecules, 2015, 16, 790-791. 
27. W. Baaziz, X. Liu, I. Florea, S. Begin-Colin, B. P. Pichon, C. Ulhaq, O. Ersen, M. Soria-Sanchez, S. Zafeiratos, I. Janowska, D. Begin and C. Pham-Huu, J. Mater. Chem. A, 2013, 1, 13853-13861.

28. M. Crespo, N. Mendez, M. Gonzalez, J. Baselga and J. Pozuelo, Carbon, 2014, 74, 63-72.

29. S. Wu, R. B. Ladani, A. J. Kinloch, Z. Zhao, J. Ma, X. Zhang, A. P. Mouritz, K. Ghorbani and C. H. Wang, Polymer, 2015, 68, 25-34

30. A. Das, M. Raffi, C. Megaridis, D. Fragouli, C. Innocenti and A. Athanassiouu, J. Nanopart. Res., 2015, 17, 1.

31. Z. Durmus, A. Durmus, M. Y. Bektay, H. Kavas, I. S. Unver and B. Aktas, J. Mater. Sci., 2016, 51, 8005-8017.

32. W. Chen, X. Pan and X. Bao, J. Am. Chem. Soc., 2007, 129, 7421-7426.

33. O. N. Shebanova and P. Lazor, J. Solid State Chem., 2003, 174, 424-430.

34. M. S. Dresselhaus, A. Jorio, M. Hofmann, G. Dresselhaus and R. Saito, Nano Lett., 2010, 10, 751758.

35. P. Dutta, S. Pal, M. S. Seehra, N. Shah and G. P. Huffman, J. Appl. Phys., 2009, 105, 07 B501.

36. G. K. Das, N. J. J. Johnson, J. Cramen, B. Blasiak, P. Latta, B. Tomanek, and F. C. J. M. van Veggel, J. Phys. Chem. Lett., 2012, 3, 524-529;

37. M. Rohrer, H. Bauer, J. Mintorovitch, M. Requardt and H.-J. Weinmann, Invest. Radiol., 2005, 40, 715-724.

38. L. Li, W. Jiang, K. Luo, H. Song, F Lan, Y. Wu and Z. Gu, Theranostics, 2013, 3, 595-615.

39.

40. N. Schleich, F. Danhier and V. Préat, J. Control. Release, 2015, 198, 35-54.

41. J. W. M. Bulte, AJR Am. J. Roentgenol., 2009, 193, 314-325.

42. Y. Wang, Quant. Imaging Med. Surg., 2011, 1, 35-40.

43. S. Trattnig, W. Bogner, S. Gruber, P. Szomolanyi, V. Juras, S. Robinson, S. Zbyn and S. Haneder, NMR Biomed., 2016, 29, 1316-1334.

44. S. K. Smart, A. I. Cassady, G. Q. Lu and D. J. Martin, Carbon, 2006, 44, 1034-1047.

45. J. Bartelmess, S. J. Quinn and S. Giordani, Chem. Soc. Rev., 2015, 44, 4672-4698.

46. D. Saha, C. L. Heldt, M. F. Gencoglu, K. S. Vijayaragavan, J. Chen and A. Saksule, Mater. Sci. Eng. C, 2016, 68, 101-108.

47. R. Alshehri, A. M. Ilyas, A. Hasan, A. Arnaout, F. Ahmed and A. Memic, J. Med. Chem., 2016, 59, 8149-8167.

48. S. Kumar, R. Rani, N. Dilbaghi, K. Tankeshwar and K.-H. Kim, Chem. Soc. Rev., 2017, DOI: 10.1039/c6cs00517a. 
49. J. J. Khandare, A. Jalote-Bahwar, S. D. Satavalekar, S. G. Bhanali, N. D. Aher, F. Kharas and S. S. Banerjee, Nanoscale, 2012, 4, 837-844.

50. H. Wu, G. Liu, Y. Zhuang, D. Wu, H. Zhang, H. Yang, H. Hu and S. Yang, Biomater., 2011, 32, 48674876.

51. F. Pineux, R. Marega, A. Stopin, A. La Torre, Y. Garcia, E. Devlin, C. Michiels, A. N. Khlobystov and D. Bonifazi, Nanoscale, 2015, 7, 20474-20488. 